\title{
Using Augmented Reality in early art education: a case study in Hong Kong kindergarten
}

AQ1 Yujia Huang (D, Hui Li* and Ricci Fong

Faculty of Education, The University of Hong Kong, Pokfulam Road, Hong Kong

(Received 17 May 2015; accepted 28 June 2015)

Innovation in pedagogy by technology integration in kindergarten classroom has always been a challenge for most teachers. This design-based research aimed to explore the feasibility of using Augmented Reality (AR) technology in early art education with a focus on the gains and pains of this innovation. A case study was conducted in a typical kindergarten in Hong Kong, with a class of four- to five-year-old children $(N=30)$ and their class teacher, ICT teacher as well as two parent volunteers. A series of art education activities using AR was designed and implemented in the class. Effectiveness of the activities was evaluated through a triangulation of semi-structured interviews with teachers, principal and parents, and surveys administered to children. The results indicated that (1) all the children could design, control and interact with the animated objects generated by the AR application; (2) all the stakeholders interviewed were supportive of this pedagogical innovation and (3) the principal, teachers and parents were concerned about the side effects of using AR in early childhood education. Possible improvements and implications to AR-based art education were also addressed.

Keywords: Augmented Reality; improving classroom teaching; pedagogical issues; applications in subject areas; country-specific developments

\section{Introduction}

Augmented Reality (AR) is one of the emerging technologies that may have the potential to bring about pedagogical innovations within this decade (New Media Consortium, $2010,2011,2012)$. AR could produce a direct vision of a physical environment from the real objects or real world combined with virtual elements at real time (Azuma, 1997). The benefits of AR in improving children's motivation and learning effectiveness have been reported by researchers among varying contexts (Cascales, Laguna, Pérez-López, Perona, \& Contero, 2013; Cascales, Pérez-López, \& Contero, 2013; empirical studies have been done in Hong Kong. AR-based art education was experimented in this feasibility study with an aim to analyse and evaluate the possibilities and potentials of using AR in early art education. 


\section{Literature review}

\subsection{AR in early childhood education}

AR has been used in early childhood education (ECE) since 2002, when Kritzenberger, Winkler and Herczeg used a mixed reality platform for German children to explore concepts of arts and computer. Later, McKenzie and Darnell (2003) conducted a case study in New Zealand, collecting the children's feedback and teachers' notes to justify how AR could help with children's storytelling. Further, Dünser and Hornecker (2007) conducted an observational study to investigate how children aged between 6 and 7 interacted with AR storybooks. A recent study in Spain found that using AR contents could improve four- to five-year-old children's learning processes and learning outcomes (Cascales, Laguna et al., 2013).

In Asia, some pilot studies have proved the potential of using AR in different domains of learning. In Taiwan, a pilot study found that AR could improve young children's pronunciation and memorisation of Chinese language (Chen, Su, Lee, \& $\mathrm{Wu}, 2007$ ). Another study (Tarng \& Ou, 2012) was an experiment of using mobile AR technology to assist primary students to learn butterfly ecology. The children could breed their own 'virtual caterpillars on host plants' and learn butterfly's life cycle by observing their growth on the smartphones. The results indicated that the AR butterfly ecological learning system was very effective. More recently in Malaysia, Tomi and Rambli $(2012,2013)$ found that the AR-supported storybooks could enhance preschoolers' story reading and learning experience. In Hong Kong, the only reported research was about using AR English Learning System to help young children to learn English in local kindergartens (Hsieh \& Lee, 2008). It was found that AR could support traditional education to achieve a human-computer interaction learning purpose. However, whether it is workable as well as effective to use AR in early childhood learning and teaching has not been empirically addressed.

In Hong Kong, all the kindergartens should follow the Guide to the Pre-primary Curriculum (GPC) (Curriculum Development Council, 2006), which regulates that the early childhood curriculum should contain six learning domains, including science and technology, and arts. It is important to note that GPC has clearly listed learning objectives, such as 'children [should] master basic exploration techniques such as observation, questioning and making assumptions' and '[be able to] express themselves through different media and materials of arts'. However, integrating information and communication technologies (ICTs) into early art activities is not an easy

job for most kindergarten teachers. The difficulties of using technology in Hong Kong kindergartens have been widely reported as the teachers were neither equipped with ICT skills nor willing to integrate them into daily teaching practices (Han, 2003; Li, 2006). Leung (2010) suggested that Hong Kong kindergarten teachers did not feel competent to design and implement ICT activities in their classrooms as they did not undergo any professional development and training for using ICTs (Leung, 2010). Therefore, this feasibility study will try to examine teachers' acceptance of using AR or other ICTs in art education by a change of teaching methodology.

\subsection{Stakeholders' views on using $A R$ in ECE}

The existing body of research conducted in western countries generally suggested that stakeholders, including teachers and parents, were supportive of using AR in ECE. Teachers believed that AR had the potential to aid children with multisensory learning 
(McKenzie \& Darnell, 2003) and could facilitate a high bandwidth of coding and communication activities between the learners and intuitive manipulation of the digital world (Kritzenberger, Winkler, \& Herczeg, 2002). Notably, parental support is essential to the successful implementation of an ICT curriculum to foster children's information literacy. Easeates (2013) found that the parents believed that using AR didactical resources could help promote their children's motivation, knowledge, 105 reading and writing, creativity and degree of satisfaction. In addition, young children's feedback is also critical to the successful implementation of AR curriculum in kindergarten. Rambli (2013) used smiley face-based scale to examine 15 five- to six-yearolds' perception of using an AR book, and found that most of them liked and enjoyed it and requested to use the AR book repeatedly. All these findings jointly indi-

110 cated that using AR in early childhood teaching might be acceptable to the stakeholders, which will be further explored by the present study.

\subsection{AR as a visual art education tool}

115 Visual arts, including two-dimensional (2D) and three-dimensional (3D) representations, can bring people with different perspectives towards their surroundings and also is the core curriculum of early art education. AR can help young children inspect $3 \mathrm{D}$ objects from different angles and enhance their understanding of different concepts. For example, Ucelli, Conti, De Amicis, and Servidio (2005) developed an AR system 120 (ARGarden) to teach children the theory of colour. The 3D virtual chameleon showed children how to get secondary colours from a combination of primary colours, and vice versa. The study showed positive effects of engaging children with AR learning and demonstrated the educational value for nurturing children's creativity and imagination. What is more, a group of scientists from the Netherlands designed a wearable AR system for art appreciation (Jurjen, Jonker, Kolstee, Rotteveel, \& Eck 2009 ) and found that AR can be 'fruitfully used to attract a broad public to displays of cultural heritage'. Furthermore, Di Serio, Ibáñez, and Kloos (2013) compared the effects of AR-based Italian Renaissance Art classes with those of traditional art lectures in a middle school. They found that students from the AR classes could achieve higher levels of concentration 130 while performing tasks and had managed to memorise the learning content easier.

It is widely believed that the integration of technology and interactive media in ECE programmes could built upon solid developmental foundations for young children, and teachers are advised to improve programme quality by intentionally leveraging the potential of technology and media for the benefit of every child (NAEYC 2013). Accordingly, 135 the powerful and motivating effects of technology in art education have been stated in a joint position statement by NAEYC (Radich, 2013). This statement has been supported by empirical evidence. For instance, an evaluation study found that using tablets could engage kindergarten children in drawing and improve their performance (Couse \& Chen, 2010). Another study found that the Interactive White Boards (IWBs) could 140 promote creativity in children (Terreni, 2010). In the study, Terreni observed that collaboration and social interactions frequently occurred when kindergarten children taught each other how to use the IWB, as well as when they shared their work.

Although these studies have jointly provided empirical evidence to support the use of AR technology in elementary settings, the potential of using AR in kindergarten art education has not been explored. As young children's colouring experiences are essential to their psychological and social development (Mayesky, 1990), this study will attempt to integrate AR into children's daily art activity, that is, colouring, and evaluate 
the possibilities and potentials of integrating AR technology into classroom instructions. Accordingly, the following questions guided this research:

(1) What are the participating children's responses to the AR art activity?

(2) What are the parents' and teachers' views on the potentials and possibilities of using AR in early art education?

(3) What are the challenges and difficulties associated with implementing AR in early art education?

\section{Methods}

\subsection{Participants}

The study was conducted in a typical Chinese kindergarten in Hong Kong. It is a nonprofit kindergarten that offers half-day programme for children from three to six years. Each class is equipped with a computer, a projector and a screen. The kindergarten is planning to use tablets in the next school year.

This study involved all the 30 young children (4-5 years old) from $1 \mathrm{~K} 2$ class, their class teacher, ICT teacher, the principal and 2 volunteer parents. All the adults and children had experiences of using smartphones or tablet PCs $(100 \%)$, but none of them had experience of using AR.

\subsection{Research design}

As an exploratory and design-based research, this study was mainly concerned about the supplemental learning effect of AR-based early art education. The testing class was taught the content of playing with AR animations supported by a mobile AR application, which was developed by Puteko Limited (2013): colAR mix (http://colarapp. com/). This application applies to both Android and iOS systems and can turn traditional 2D colouring pages into 3D models (AR objects) that literally jump off the page (Tables 1 and 2). To test the different impacts of AR between whole-class teaching and small group activity, we deliberately planned three sessions of 'colAR mix' workshops within two weeks (one whole-class teaching and two small group activity sessions). Each session lasted for 20 to 30 minutes.

\subsubsection{The whole-class 'colAR mix' workshop}

As shown in Table 1, before the workshop, we randomly selected 1 theme of colouring pages and printed 32 copies from colAR's website. During the class, the teacher showed all the colouring pages to the children and let them choose their favourites. When children finished colouring, the teacher asked who would want to share his/ her coloured masterpiece with their peers. We connected an iPad mini to the class projector after a child's sharing. We then launched the colAR application on iPad, pointing the built-in camera at the child's picture. Instantly, children would be able to see the image coloured and animated into a pop-up 3D object.

\subsubsection{The small group 'colAR mix' workshop}

The small group workshops were conducted among four children and a pair of children (Table 2) separately in two sessions. We downloaded 60 copies of 'dot day' sheets 
Table 1. The whole-class 'colAR mix' workshop.

200

205

210

215

220

Step 1
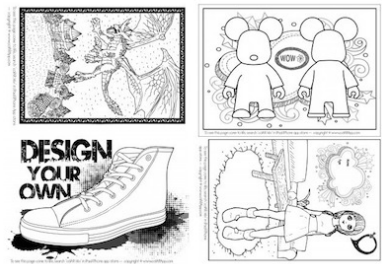

Step 2

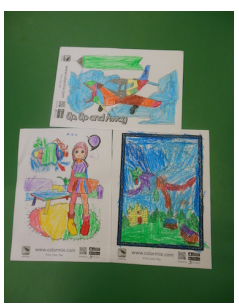

Step 3

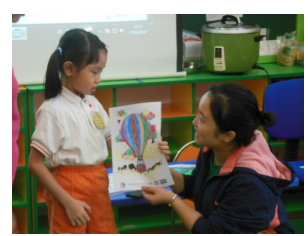

Step 4

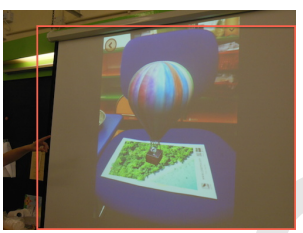

Step 5

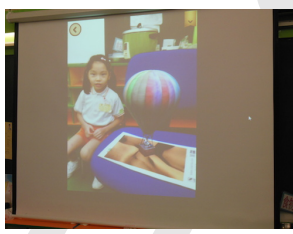

Step 6

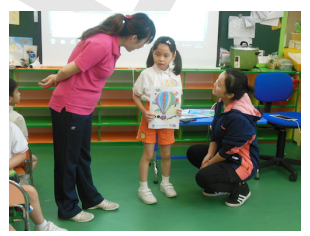

Teacher demonstrated all the colouring sheets and let children choose their favourite one

Children choose different crayons and colour pencils to finish their work

Ask children to share his/her colouring work with classmates

Demonstrate the child's work on the screen using colAR mix application on iPad

Teach children how to interact and take photos with their own AR paintings

Encourage children to talk about what they saw, heard and what happened in their AR work 
Table 2. The small group 'colAR mix' workshop.

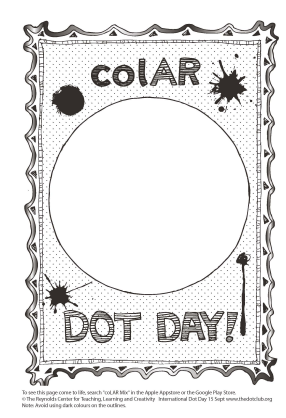

260
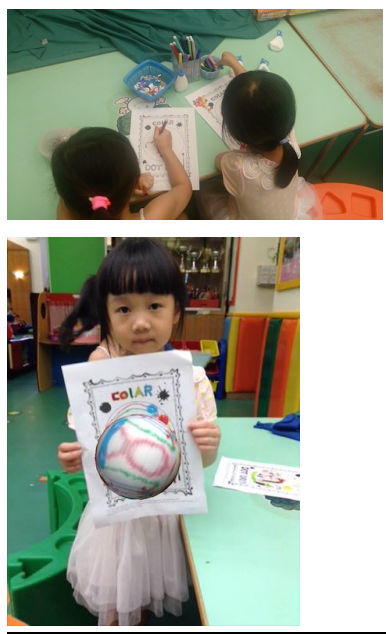

Give the children the 'dot day' sheet to paint whatever they want

Children use different painting tools including crayons, colouring pencils and stickers to create their masterpieces

Demonstrate each child's 'dot day' sheet by using colAR application and ask them to share what their balls are doing. Then children could freely explore their AR work with iPads

(Table 2) from the colAR website, on which children can draw whatever they want in the circle. And the group of children could freely explore their AR work with two iPads offered by the researcher, and interact with each other's AR work on the iPad interface. They learned how to take photos for each other with iPad.

\subsubsection{Stakeholders' interviews and surveys}

After three consecutive sessions of AR activities, we conducted semi-structured interviews with the class teacher, the principal, the ICT teacher and the two parents. Each interview lasted for 10-15 minutes and was audio-recorded. Then we randomly selected 11 children to join a survey mainly on their likeability of AR workshops.

\subsection{Data collection}

Data were collected through multiple sources (the teacher, the principal, the ICT teacher, two parents and children) and in multiple types (observation, interview and documents).

\subsubsection{Participant observation}

Guest, Namey, and Mitchell (2103) suggested that the most traditional use of participant observation was at the exploratory stages of the research on a new topic, 
culture, venue, or behaviour. Since it was the first time for all the participants to come into contact with AR, we took part in all the workshops and conducted participant observation. We made observation notes, and also took photos and videos during each AR workshop session. Altogether 70 pictures and 3 short videos were taken to document this research for further analysis.

\subsubsection{Qualitative data}

The piloted topic guide (Table 3) was used to explore the participants' acceptance to AR-based learning and how they would like to use it (refer to Simon \& Nemeth, 2012).

\subsubsection{Quantitative data}

We measured children's likeability with five close-ended questions and one question with smiley face-based scale from 'I like it so much' to 'I do not like it at all' (Rambli et al., 2013). All the questions (Table 5) were read by the researcher, and the children were asked to answer 'yes' or 'no' or to point at the appropriate column to complete the survey.

\subsection{Data analysis}

\subsubsection{Qualitative data analysis}

The interviews were transcribed verbatim in Chinese, and qualitative content analysis (QCA) was employed to analyse the data (Schreier, 2012). The interview transcripts

Table 3. The interview protocol.

Teachers' and principal's interview outline

Does 'colAR workshop' program meet most of the criteria for development appropriateness?

Are you and children likely to use it often and purposely?

Will you have the appropriate level of technology awareness and skills to use it well?

Is the overall variety of programs diverse enough, or is there an abundance of programs

that support one skill/concept/contend area and too few that support others?

Do you have the budget to support the cost and the professional development needed to support its use?

Will you have to pay to upgrade the application?

Say is it a good fit for your art class or technology class?

Will it help your staff members meet their objectives?

Would you like to use it among other age groups in your kindergarten and shared among the staff members?

Is there built-in technical support?

Do you think there need hands-on training, and if so, how much will it cost?

Is your program set up to support and monitor its use?

Is it safe?

Parents' Interview outline

Are you in favor of AR activities in your children's class? Why?

What benefits/drawbacks that you can think of AR in children's class?

Do you think it is hard?

Are you and children likely to use AR often and purposely?

Do you have the budget to support the cost needed to support its use?

Is it safe?

Is it hard for you? 
Table 4. Categories of perceptions towards AR in kindergarten.

1. AR acceptance

2. Pros of AR

3. Cons of AR

4. The role of AR (ICT)

5. Factors influencing AR adopted in kindergarten

Table 5. Categories of children's responses.

\begin{tabular}{ll}
\hline Categories & \\
\hline Likeability & 1. Do you like using it? \\
& 2. How much do you like it? \\
Willingness to & 3. Do you want to play it again? \\
persistence & 4. Do you want to have these coloring pages? \\
Ease of learning & 5. Is it easy or hard to use? (E/H) \\
Favourite part & 6. Which part do you like best: Painting, 3D, or interact with 3D? (P/ \\
& 3D/I)
\end{tabular}

were coded and grouped into five categories (Table 4) and subcategories depending on their differences and similarities. All the coding work was done with Nvivo 10.

\subsubsection{Quantitative data analysis}

All the responses made by the children were classified into the following four categories (Table 5).

\section{Results}

\subsection{Young children's responses to AR-based art activity}

\subsubsection{Acceptance of the activity}

The videotaped observation indicated that all the children enjoyed the AR-based learning activities. In particular, when the AR aeroplane suddenly appeared on the big screen, children began to scream and yell, laughed loudly and even jumped up from their chairs to imitate how an aeroplane flies (Figure 1). The AR objects gave them overwhelming inspiration and stimulation, engaging them deeply in the learning process. They shouted to describe how the AR objects looked like to their peers 'See! It is jumping!', 'It is flying in the sky!' and so on.

In the survey, all of the children (100\%) chose 'Yes' to the first question 'Do you like playing with it', and the highest level of 'I like it so much' $(100 \%)$ on the smiley scale of the second question. When being asked the reason why they chose the happiest face to this activity, some children said the AR objects 'appeared by magic' or 'it is so funny'. Other responses included, 'it suddenly appears' and 'it seems like it was flying'.

\subsubsection{Willingness to repeat the activity}

Altogether 10 out of 11 children (90.9\%) chose 'Yes' to the question 'do you want to play it again', whereas one child said 'no' with no specific reasons. In addition, when 


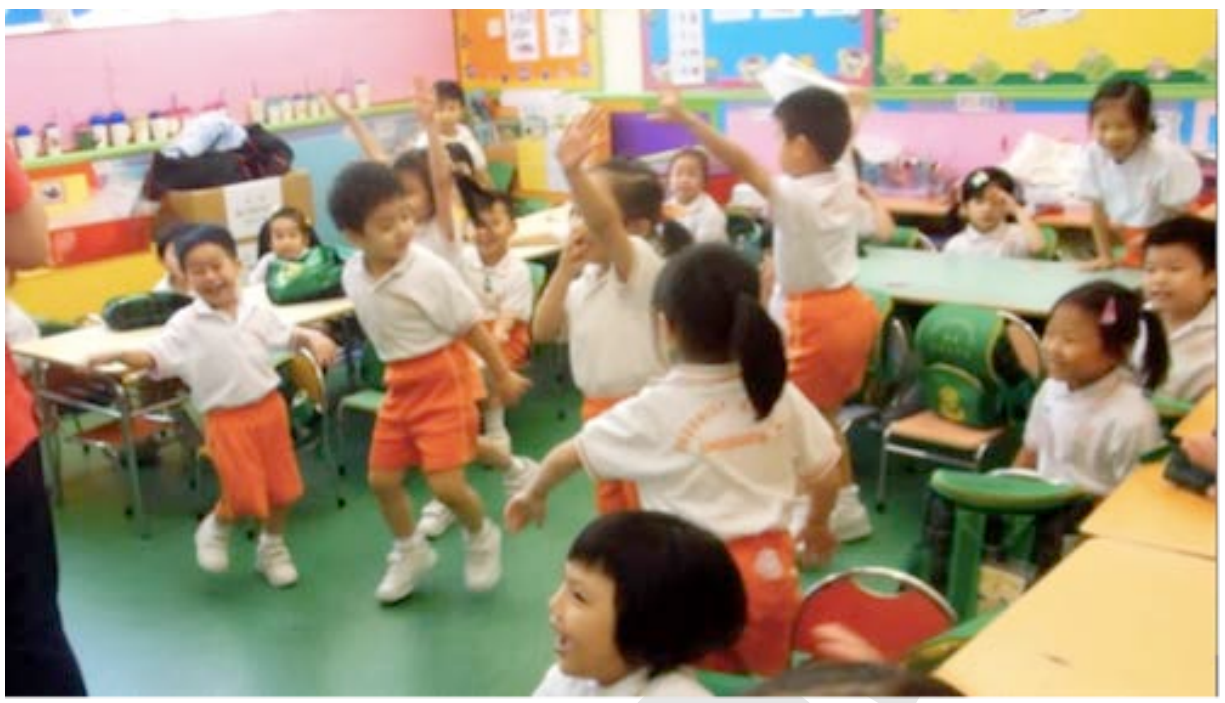

Figure. 1. Children were spontaneously dancing and laughing when they saw the AR aeroplane (screenshot from class video).

being asked 'Do you want to have more of those coloring pages', two of them chose willing to play the game after about 10 minutes, and asked for playing other games. However, most children showed great passion to such AR experiences.

\subsubsection{Difficulty of the activity}

There were 10 out of the 11 children (90.9\%) who answered 'easy' when being asked 'Do you think it is easy or hard to use'. Videotaped classroom observation found that during the small group activities, all the children could hold iPad properly and pointed the camera to their pictures, waiting for the AR images to appear. They rotated the device and viewed the AR objects from different angles. But some of them encountered difficulties such as standing too close to the picture that the camera could not recognise the whole page of image, or they did not know how to find the correct application on the homepage after quitting the application. But almost all of them were able to ask for teachers' help when encountering any 430 troubles.

\subsubsection{Their favourite part of the activity}

For the last question, most children (63.6\%) answered 'turning it to 3D images', while three of them $(27.2 \%)$ chose 'take photos' and one $(9.1 \%)$ said she 'only likes the dinosaur' in the picture. Videotaped classroom observation indicated that the children kept showing high enthusiasm throughout the whole series of activities, that is, during colouring, AR class demonstration and taking photos with AR objects. They were highly engaged in this fresh new experience all the time. They asked for 440 more colouring pages and waited with patience for another AR object to appear. Moreover, they would actively take photos with AR images in the front of all the 
classmates. That, to some extent, has enhanced their confidence and imagination through the learning process.

\subsection{Stakeholders' views on using $A R$ in kindergarten}

\subsubsection{The acceptance of AR-based learning}

AR is a brand new ICT experience for all the stakeholders of this kindergarten. All of the participants showed positive attitude towards AR technology as well as their concerns about its adoption in kindergarten. They all believed it was an interesting experience. The class teacher, ICT teacher and one parent expressed their willingness to try again with more colouring pages and they both admitted that it was very popular as well as beneficial for children to know some useful emerging technology. The following excerpts from transcripts of the interviews provide an illustration of their positive attitudes:

It is based on children's art work combined with high technology ... very attractive! Children are so happy today and I will try it again if time permits. (Teacher)

I think it is more interesting for teachers to teach with than holding a sheet of paper ... At least children can have different experiences. (ICT teacher)

I think it is another way for them to paint and it is very special. I can accept this kind of activity in K2. (Parent B)

Meanwhile, however, the principal and another parent expressed their concerns about the side effects of using AR, which were mainly about children's addiction and the lack of human interaction involved if insufficient guidance is offered. The following quotes showed their concerns about it:

It is novel for children and definitely a good medium ... the effects are instant like magic ... I think if we can use it properly, it can fulfill children's holistic development. (Principal)

It is $\mathrm{OK}$ for them to know some special technology like this, but they cannot spend too

\subsubsection{The pros and cons of AR-based learning}

The principal and the participating teachers expressed that the real-time effect of AR technology could provide great fun and stimulation compared to regular colouring experience for children and has the potential to enhance children's learning interests and self-confidence. They believed that AR is a useful tool for teachers to improve their teaching effectiveness especially when they are teaching some abstract concepts. It could also deepen children's understanding in specific teaching units and facilitate children's cognitive development. They commented on the benefits of using AR as follows:

Honestly, it is my first time to see this kind of technology. And I think it was better than our regular technology activities like simply watching cartoons in the classroom. Because you can base on children's physical coloring sheets ... children are so excited to see his artwork pop up as a concrete thing on the big screen, it is another way to concrete 
children's learning materials and express their feelings. Their delight and joy differed from the way they react to normal activities. (Teacher)

Children are proud of the work displayed in the classroom especially in this way ... they like moving things so much ... it can catch their attention immediately and it can definitely provoke their learning interests. (Principal)

However, the participating teachers and the principal also discussed the technical disadvantages of this AR application. First, it might have some negative effects on young children's social/visual/motor development. All the interviewees stressed that communication skills and language development were utmost important in the early years. They worried that children might be more interested in playing with tablets than interacting with peers. But when the interviewer asked them whether using AR technology could lead to insufficient communication with others or not, they hold the same position that children's social development mainly depends on parents' gui505 dance and how teacher organises this kind of ICT activities. Another concern was the visual impairment potentially caused by children's use of smart devices. Both parents said they would control the time spent on tablet. One of them suggested that 10-15 minutes was enough for children per day. The principal believed that the visual impairment in early childhood might be permanent and would affect their learning and daily

510 life. She was also worried that the development of fine motor and gross motor skills would be affected by using ICT, as shown in the following quote:

Children in Hong Kong were obsessed with playing touch screens because the contents were indeed attractive. From K1, children start to know how to tap the screen with one finger but not with the coordination of different fingers. Therefore, they would not like to play outside... The cognitive development lasts for a lifetime, but if children miss the critical period of motor development, it is hard for them to fix it later. (Principal)

Second, there are some limitations of 'colAR mix' application. The participating teachers and the principal shared the same opinions about the drawbacks of 'colAR mix' application. They tended to believe that the limited prototypes might have restricted young children's creativity and imagination. Children could only select the specified colouring pages, and they could not add new elements to the pictures. In addition, they argued that children's interests would gradually diminish after playing with it for several times. The teacher also suggested if there were some other functions like recording children's voices into the system, or interacting more with peers, it could be better.

\subsubsection{The role of $A R$ in early art education}

530 The role of AR is defined as how stakeholders view on the four topics related to AR including (1) AR's attributions; (2) when to use AR; (3) for what purpose to use AR and (4) for whom to use AR. All the interviewees admitted that the accessibility of ICT in our daily lives was extremely high. The teacher, the ICT teacher and parents regarded AR as a kind of updated ICT knowledge for children to learn and believed that it might be an unavoidable topic in the kindergarten curriculum. Besides, the parents expected more academic outcomes related to using AR or engaging in other ICT activities:

ICT can supplement other teaching materials to make knowledge more amusing and attractive ... it is necessary to adopt ICT in kindergartens especially when teachers 
need to enhance children's engagement in learning. But AR may not be the priority for teachers. Because teachers in this kindergarten are only required to master some basic computer skills like Microsoft Office. (ICT teacher)

At least they can learn new things; learning is definitely good for them. It would be beneficial to their study and make them more competitive in the future. (Parent B)

In addition, the teacher and principal commented that AR might be a new teaching tool, but with challenges to overcome. They believed that it should be used to fulfil children's needs and promote children's holistic development. Nevertheless, they also claimed that they would not take ICT activities as important as other teaching activities, because the teaching effects would mainly depend on how teachers integrate it into classroom instructions:

There is not an urgent need for children to acquire ICT skills now, so I have my focus and priorities. AR can be a good teaching medium to enhance the teaching effect but not as necessary as other regular activities. (Principal)

\subsubsection{The challenges and difficulties}

The participants reported four major challenges to the successful implementation of AR in early art education in Hong Kong context. The first one is the lack of professional development on ICT integration for kindergarten teachers. In this kindergarten, for instance, the principal and teachers varied greatly in ICT literacy. In general, young teachers were more willing and feel more confident to use new technology in daily teaching, but the experienced teachers were not so literate in ICT. To make things worse, there is no training on ICT integration and pedagogies, so even young teachers also feel that it might be a challenge:

Before I know how to use this technology, it may bother me because I need to know how to (apply it to) achieve my teaching objectives. (Teacher)

If teachers know how to design and conduct this activity to overcome its one-way communicative attribution, it can also be a good teaching material. But if not, then it might just a kind of computer game. (Principal)

The second challenge is the lack of professional training in art education. Both teachers and the principal admitted that the training programme for kindergarten teachers in Hong Kong was insufficient, especially in arts and music. Therefore, teachers would very rarely conduct art activities with the aid of ICT. It was also troublesome for them to design a curriculum which combines art with ICT. The following quote is a further explanation made by the principal:

Arts, in terms of symbols, are difficult for most people. Especially for kindergarten teachers in Hong Kong, most of them do not possess professional skills on how to teach art and music. We cannot blame teachers because our training program is not inclusive.

So teachers' art literacy is weaker compared to other teaching skills. (Principal)

The third challenge is the lacking of resources allocated for AR. Teaching time is very limited in Hong Kong kindergartens, as the programme only lasts three hours a day. All the interviewees, except the ICT teacher, expressed the same concern that children should not spend too much time on ICT activities no matter how attractive they 
are. Besides, the teachers and principal both reported that they could not spare enough time to engage in such ICT initiatives during the three-hour half-day kindergarten programme:

If you did this project last month, there was no time for you. I have almost finished the teaching task now. Regularly, time is precious for me, because I need to cover all the six learning areas in three hours according to the curriculum requirements. So I must keep an eye on each activity. (Teacher)

Lastly, the budget for daily teaching is also very limited. Both the teachers and the principal expressed that they would not spend too much money on ICT equipment. They claimed that they were more willing to spend on traditional toys and teaching materials. The principal even argued that ICT could not meet all domains of children's development compared to other traditional learning materials.

\section{Discussions}

\subsection{Young children's responses to AR-based art activities}

The present study found that the AR-based art activities had promoted excitement, engagement and enjoyment in the participating children. All the children enjoyed the activities very much. The AR-based art activities have triggered young children's 610 imagination, for instance, as they imitated the flying plane on the screen. Their reactions to the AR-based animation were really different from those to seeing a plane printed on a piece of paper.

It is widely believed that fun and interactive learning must be one of the powerful pedagogical factors that could create an interactive and engaged learning environment (Rambli, 2013). The results of this study indicated that AR-based art education could be a workable solution to improving the early childhood pedagogies in Hong Kong. However, this study has only examined young children's acceptance and responses to the AR-based art activities, but did not evaluate its effectiveness in promoting children's art performance. Follow-up studies are needed to further address this issue.

\subsection{Parents' and teachers' views on the AR-based art activities}

The present study found that all the stakeholders showed relatively high acceptance to 625 this emerging technology and recognised its benefits. To some extent, this feasibility study was successfully executed with a series of AR-based art activities conducted in a typical kindergarten in Hong Kong. In line with the existing studies (Caseales, 2012; Dünser, 2007; Kerawalla, Luckin, Seljeflot, \& Woolard, 2006; Rambli, 2013; Wu, Lee, Chang, \& Liang, 2013), this study has further indicated that AR can be a powerful

630 and motivating instrument to be widely used in the Chinese context. In particular, the teachers and principal agreed that AR had the potential to enhance instructions in a novel and probably transformative way (Dunleavy, Dede, \& Mitchell, 2009). They also showed strong interests to incorporate the technology in teaching.

However, compared to the reported positive attitudes towards AR in other contexts (Cascales, 2012; Dünser, 2007; Kerawalla et al., 2006; Rambli, 2013; Wu et al., 2013), some relatively negative views were shared by the teachers and parents in Hong Kong. The present study found that all the interviewees were concerned about the side effects 
of using AR in young children's learning. This finding indicated that Chinese adults held a dialectical view towards AR-based art education.

\subsection{The gains and pains of using $A R$ in early art education}

This study found that AR could be a useful and attractive teaching tool in both wholeclass and small group activities in a Hong Kong kindergarten. This has made the daily teaching and learning more enjoyable and interesting for both teachers and children. Furthermore, this study also found that using AR-based interface could improve existing learning methods and have the potential to enhance children's learning interests. In line with the existing literature (Jurjen, Pieter, Yolande, Joachim, \& Wim, 2010 ; Kerawalla et al., 2006), for instance, this study found that children were able to build a new understanding of the target concepts when exploring the AR objects from different perspectives. Therefore, the AR interface could provide a superior level of cognitive access to complex visualisations compared to those computer interfaces or other traditional art interfaces.

Some major challenges, however, were also found in the present study. First, teachers are playing the most important role in initiating a pedagogical innovation, and must have basic ICT skills so that they could and would try using any new technologies in their class. But Hong Kong teachers did not get enough professional training in this regard (Han, 2003; Leung, 2010). Second, time was found to be the context-specific limitation. Both the principal and teachers admitted that it was very difficult to

660 arrange time for these AR-based activities as every kindergarten has a very tight timetable for their half-day programme (three hours per day). However, AR-based teaching needs to deliver curriculum content within the same time span as traditional teaching does (Dünser, 2007). So, in reality, teachers tend to exclude ICT activities in order to accomplish their teaching tasks in time.

\subsection{Possible improvements and future work}

$\mathrm{AR}$ is an emerging teaching technology (especially the mobile AR applications) in the field of ECE. The current studies are relatively simple and exploratory with small sample sizes ( $W_{\mathbb{t}_{2}}$ 2013). So is the present study. Nevertheless, this study could serve as a prototype for further empirical investigations into the teaching effectiveness of AR technology in early art education.

Besides, the findings of this study could indicate some possible improvements in the AR-based early art education. First, the AR-based learning contents should be more flexible to meet the individual needs and paces in learning. The AR application should give more control to teachers so that they could add and remove elements from the prototype, or even change the speed of the animations. This is also suggested by Dünser (2007). Second, the AR-based learning activities must be carefully designed to ensure that learning objectives could be achieved in a short period of time. The curriculum design should also focus on children's creativity. Lastly, more comprehensive and rigorous evaluation studies should be conducted in the future to verify the positive effects of AR-based art education found in this study.

This study has several limitations. It was just a case study with a small sample, and the AR workshops only consisted of three sessions. A larger sample with a reliable and 685 valid instrument is needed to further evaluate how AR technology can influence children's learning outcomes in art education. In addition, pedagogical innovations in other 
learning areas such as early literacy and numeracy could also be tried out and evaluated to consolidate the educational effects of AR learning environment.

690

\section{Conclusions}

The aim of this study is to explore the feasibility of integrating AR technology into art education in a Chinese kindergarten in Hong Kong. All the participating stakeholders showed big interests and high acceptance after a series of AR-based art activities. Children's responses and performances jointly proved that AR could be an engaging and attractive teaching tool in ECE. However, this study also found that the stakeholders had some concerns about the side effects of using AR in young children's learning. In Hong Kong, due to the lack of ICT and art training, it might be a huge challenge for early childhood educators to design and integrate AR into daily teaching activities at present and even in the near future.

\section{Disclosure statement}

No potential conflict of interest was reported by the authors.

\section{ORCID}

Yujia Huang (D) http://orcid.org/0000-0001-7372-4737

\section{References}

Azuma, R. (1997). A survey of augmented reality. Presence: Teleoperators and Virtual Environments, 6(1), 355-385.

Cascales, A., Laguna, I., Pérez-López, D., Perona, P., \& Contero, M. (2013). An experience on natural sciences augmented reality contents for preschoolers. In Virtual, augmented and mixed reality. Systems and applications (pp. 103 112). Springer Berlin Heidelberg.

Cascales, A., Pérez-López, D., \& Contero, M. (2013). Study on parent's acceptance of the augmented reality use for preschool education. Procedia Computer Science, 25, 420-427.

Chen, C. H., Su, C. C., Lee, P. Y., \& Wu, F. G. (2007, July). Augmented interface for children Chinese learning. In Seventh IEEE Internation Conference on Advanced Learning Fechologies, 2007. ICALT 2007 (pp. 268 270). IEEE.

Cheng, K. H., \& Tsai, C. C. (2014). Children and parents' reading of an augmented reality picture book: Analyses of behavioral patterns and cognitive attainment. Computers \& Education, 72, 302-312.

Couse, L. J., \& Chen, D. W. (2010). A tablet computer for young children? Exploring its viability of early childhood education. Journal of Research on Technology in Education, 43(1), 75.

Curriculum Development Council. (2006). Guide to the Pre-primary Curriculum. Hong Kong: Government Print.

Di Serio, Á., Ibáñez, M. B., \& Kloos, C. D. (2013). Impact of an augmented reality system on students' motivation for a visual art course. Computers \& Education, 68, 586-596.

Dunleavy, M., Dede, C., \& Mitchell, R. (2009). Affordances and limitations of immersive participatory augmented reality simulations for teaching and learning. Journal of Science Education and Technology, 18(1), 7-22.

Dünser, A., \& Hornecker, E. (2007). An observational stly of children interacting with an allg mented story book. In Technologies for E-learning and digital entertainment (pp. 305 315). Springer Berlin Heidelberg. for applied research. Thousand Oaks, CA: SAGE Publications. 
Han, C. C. W. (2003, July). Challenges of using ICT in Hong Kong early childhood settings. In Young children and learning technologies: Selected papers from the International Federation for Information Processing Working Group 3.5 open conference. Sydney, Australia.

Hsieh, M. C., \& Lee, J. S. (2008). AR marker capacity increasing for kindergarten English learning. Hong Kong: National University of Tainan.

Johnson, L., Adams, S., \& Cummins, M. (2012). The NMC horizon report: 2012 higher education edition. Austin, TX: The New Media Consortium.

Johnson, L., Levine, A., Smith, R., \& Stone, S. (2010). The 2010 horizon report. Austin, TX: The New Media Consortium.

Johnson, L., Smith, R., Willis, H., Levine, A., \& Haywood, K. (2011). The 2011 horizon report. Austin, TX: The New Media Consortium

Jurjen, C., Pieter, J., Yolande, K., Joachim, R., \& Wim, V. E. (2010). Augmented reality for art, design and cultural heritage - system design and evaluation. EURASIP Journal on Image and Video Processing, 2009.

Kerawalla, L., Luckin, R., Seljeflot, S., \& Woolard, A. (2006). 'Making it real': Exploring the potential of augmented reality for teaching primary school science. Virtual Reality, 10(3-4), $163-174$.

Kritzenberger, H., Winkler, $\mathrm{T}$., \& Herezeg, M. (2002). Collaborative and consture learning of elementary school children in experimental learning spaces along the virtuality continutm. In mensch \& computer (Vol. 2002, pp. 115 124).

Leung, W. M. (2010). Young children's learning with information and communication technologies in Hong Kong kindergartens. $\mathrm{PhD}$ thesis, Victoria University, Melbourne.

Li, H. (2006). Integrating ICT into the early childhood curriculum: Chinese principals' views of the challenges and opportunities. Early Education and Development, 17(3), 467-487.

Mayesky, (1990). Creatives for y (4thed.). Delmar.

McKenzie, J., \& Darnell, D. (2003). The eyeMagic book. In A report into augmented reality storytelling in the context of a children's workshop. Christchurch: Centre for Children's Literature, Christchurch College of Education.

Radich, J. (2013). Technology and interactive media as tools in early childhood programs serving children from birth through age 8. Every Child, 19(4), 18.

Rambli, D. R. A., Matcha, W., \& Sulaiman, S. (2013). Fun learning with AR alphabet book for preschool children. Procedia Computer Science, 25, 211-219.

Schreier, M. (2012). Qualitative content analysis in practice. London: Sage Publications.

Tarng, W., \& Ou, K. L. (2012, March). A study of campus butterfly ecology learning system based on augmented reality and mobile learning. In 2012 IEEE seventh international conference on Wireless, Mobile and Ubiquitous Technology in Education (WMUTE) (pp. 6266). IEEE.

Terreni, L. (2010). Adding new possibilities for visual art education in early childhood settings: The potential of interactive whiteboards and ICT. Australasian Journal of Early Childhood, 35(4), 90-94.

Tomi, A. B., \& Rambli, D. R. A. (2013). An interactive mobile augmented reality magical playbook: Learning number with the thirsty crow. Procedia Computer Science, 25, 123-130.

Ueelli,G.,Conti,G., De Amicis, R., \& Servidio, R.(2005). Leaning wing alment reality nology: Multiple means of interaction for teaching children the theory of colours. In Intelligent technologies for interactive entertainment (pp. 193 202). Springer Berlin Heidelberg. challenges of augmented reality in education. Computers \& Education, 62, 41-49. 